See discussions, stats, and author profiles for this publication at: https://www.researchgate.net/publication/281382431

\title{
Effects of the fractal structure and size distribution of flocs on the removal of particulate matter
}

Article in Desalination and water treatment · August 2015

DOI: 10.1080/19443994.2015.1081833

CITATIONS

7

5 authors, including:

André Oliveira

Universidade Federal de Uberlândia (UFU)

12 PUBLICATIONS 20 CitATIONS

SEE PROFILE

Rodrigo Moruzzi

São Paulo State University

96 PUBLICATIONS 197 CITATIONS

SEE PROFILE
READS

99

Pedro Augusto Grava da Silva

São Paulo State University

4 PUBlications 9 Citations

SEE PROFILE

Some of the authors of this publication are also working on these related projects:

Análise das condições de macrodrenagem em uma bacia hidrográfica urbanizada no Município de Rio Claro (SP): O caso do Córrego da Servidão View project

Microalgae as a solution for the recovery of nutrients from high-load sanitary wastewater View project 


\section{Effects of the fractal structure and size distribution of flocs on the removal of particulate matter}

André Luiz de Oliveira, Pamela Moreno, Pedro Augusto Grava da Silva, Marcelo De Julio \& Rodrigo Braga Moruzzi

To cite this article: André Luiz de Oliveira, Pamela Moreno, Pedro Augusto Grava da Silva, Marcelo De Julio \& Rodrigo Braga Moruzzi (2015): Effects of the fractal structure and size distribution of flocs on the removal of particulate matter, Desalination and Water Treatment, DOI: 10.1080/19443994.2015.1081833

To link to this article: http://dx.doi.org/10.1080/19443994.2015.1081833

Published online: 28 Aug 2015.

Submit your article to this journal

Џ Article views: 6

Q View related articles $\asymp$

View Crossmark data ¿ 


\title{
Effects of the fractal structure and size distribution of flocs on the removal of particulate matter
}

\author{
André Luiz de Oliveira ${ }^{a}$, Pamela Moreno ${ }^{a}$, Pedro Augusto Grava da Silva ${ }^{a}$, \\ Marcelo De Julio ${ }^{\mathrm{b}}$, Rodrigo Braga Moruzzi ${ }^{\mathrm{a}, *}$ \\ ${ }^{a}$ LATARE, DEPLAN, Instituto de Geociências e Ciências Exatas, UNESP-Univ. Estadual Paulista, Campus de Rio Claro, Avenida \\ 24-A, $n^{\circ}$ 1515, Bela Vista, Rio Claro, SP CEP 13506-900, Brazil, Tel. +55 343239 4170; email: andreoliveira@feciv.ufu.br \\ (A.L. de Oliveira), Tel. +55 193526 9339; email: pamys_15@hotmail.com (P. Moreno), pedroagrava@gmail.com (P.A.G.da Silva), \\ rmoruzzi@rc.unesp.br (R.B. Moruzzi) \\ ${ }^{b}$ Aeronautic Institute of Technology, Civil Engineering Division (ITA-Instituto Tecnológico de Aeronáutica, Divisão de Engenharia \\ Civil), CTA-ITA_IEI, Praça Marechal Eduardo Gomes, 50, Vila das Acácias, São José dos Campos, São Paulo CEP 12.228-900, \\ Brazil
}

Received 15 December 2014; Accepted 4 August 2015

\begin{abstract}
This study sought to evaluate the effect of form and particle size distribution of formed flocs during flocculation on the removal of particulate matter (PM) by settling. The understanding of the intrinsic processes of water treatment is fundamental for the improvement of these processes, and this understanding is often limited by the use of indirect measurements. For this reason, this study evaluated the relationships among the morphology, particle size distribution (PSD), and particle volume distribution of flocs formed with mean flocculation velocity gradients $\left(G_{f}\right)$ from 20 to $60 \mathrm{~s}^{-1}$ and settling velocities from 0.5 to $5.0 \mathrm{~cm} \mathrm{~s}^{-1}$ at flocculation times $\left(T_{f}\right)$ from 10 to $60 \mathrm{~min}$. A correlation analysis of all of the parameters was performed to identify the most significant direct measurement for characterizing the removal of PM. Strong correlations among parameters were observed when considering the variation with $G_{f}$ for a given $T_{f}$, and moderate correlations were observed when considering the variation with $T_{f}$ for a given $G_{f}$. The strong correlations that resulted from the alteration of $G_{f}$ were a consequence of the significant changes in the morphological characteristics, PSD, and PVD of the flocs. The lower strengths of the correlations with the variation in $T_{f}$ can be explained by the rapid attainment of the equilibrium steady-state between aggregation and disaggregation forces.
\end{abstract}

Keywords: Particulate matter; Settling; Morphology; Particle size distribution; Particle volume distribution

\section{Introduction}

The use of non-specific parameters is considered to be the main limitation for the improvement of

${ }^{*}$ Corresponding author. treatment systems that utilize a solid/liquid separation process. The exact nature and size of particulate matter (PM) are unknown when indirect measurements are analyzed. A great step forward was accomplished when direct evaluations of particle shape and the particle size and volume distributions of PM were

1944-3994/1944-3986 ㄷ 2015 Balaban Desalination Publications. All rights reserved. 
first employed to evaluate the performance of treatment systems [1-4]. Within physical-chemical water treatment methods, flocculation is the primary stage during which the distribution and shape of PM are altered before it is then further removed in solidliquid separation units. Flocculation usually involves two stages: transport and aggregation [5,6]. Aggregation depends on a series of short-range forces that are related to the nature of the particle surfaces. Therefore, flocculation is the process by which collisions among coagulated colloids form larger aggregates $[7,8]$.

The success of a physical-chemical water treatment process is directly linked to the success of the integrated coagulation/flocculation process. Because of this linkage, it is important to establish direct measurements of flocculation efficiency and to avoid conducting all system control and monitoring based on indirect measurements, such as turbidity. Direct measurements of flocculation efficiency, such as particle size distribution (PSD), particle volume distribution (PVD), and floc morphological characteristics, may provide important information (which is omitted when indirect measurements are used), thus helping designers to improve flocculation applied to solid-liquid separation. The growth of flocs to a certain limit and the attainment of steady state for a given shear condition [9] can be directly followed in a flocculation chamber.

The PSD, PVD, fractal diameter $\left(D_{f}\right)$, and mean diameter $\left(D_{\text {mean }}\right)$ can be applied directly, individually, or in combination, to control coagulation/flocculation, as observed by Hatukai et al. [10]; Wu and He [11]; and Yao et al. [12], among others. Direct measurements of flocculation performance are extremely valuable in terms of collecting parameters that are representative of the particle distribution and morphology of flocs because these characteristics are determinant for the correct use of the phase-separation technology and control the global efficiency of particle removal in water treatment systems. The appearance of flocs in treatment units and the achievement of the stability stage, for a given pre-established configuration, can be monitored by following these characteristics.

The stability of the flocs in suspension depends on how easily they break apart, which is directly related to the strength and the number of bonds that hold the flocs together. Aggregation is stronger than disaggregation during the rapid initial formation of microflocs; however, disaggregation becomes more important as the floc size increases. Therefore, under steady-state conditions, the floc size is controlled by the shear/stress conditions in the liquid medium. If the shear rate exceeds the critical level when under a steady state, the flocs will disaggregate, and a new steady state will be achieved. Under certain conditions, the broken flocs will not aggregate if they are subjected to a higher shear rate [9]. Therefore, the limited growth of flocs is typically considered to be caused by the process of disaggregation, which occurs independently from coagulation, and is faster than coagulation. Disaggregation is the result of hydrodynamic stresses that occur because of the relative movement of the dispersed phase and the dispersion media [9].

According to Brakalov [13], the most widely used criterion to verify the validity of a limited growth model is the comparison between expected and experimental values of the maximum size of aggregates (verified by the direct measurement of flocculation performance) at a given shear rate (mean velocity gradient). The relationship between these variables is typically given in the form of Eq. (1):

$d=C G^{-\beta}$

where $d$ =maximum size of the aggregate; $C$, $\beta=$ constants; $G=$ mean velocity gradient.

Different models provide different values of $\beta$. Thus, the most likely floc disaggregation mechanism is determined according to experimental data. Experimentally obtained $\beta$ values vary between 0.3 and 1 , with a higher frequency between 0.5 and 0.8 .

Regarding their shape, flocs obtained from water treatment systems have a fractal structure [14,15]. Other properties, such as the apparent density and settling velocity, are also function of the fractal nature. The fractal dimension (in terms of area) can be summarized by the relationship between the area A of a particle (as cross-section or plane projection), a characteristic measure of size $(L)$, and the fractal area dimension $\left(D_{f}\right)$, according to Eq. (2) [16].

$A \sim L^{D_{f}}$

$D_{f}$ is usually an integer number for Euclidean objects [17], but $D_{f}$ values do not follow Euclidean geometry for fractal objects. More compact aggregates have a greater fractal dimension, while aggregates with a looser structure have a smaller fractal dimension [17].

Various studies [10-17] have related particle characteristics with floc particle distribution and morphology; however, knowledge of the significance of these measurements in terms of their relationships to separation efficiency is scarce. Therefore, the main objective of this study was to evaluate the effect of form and PSD on the removal of PM by settling, 
obtained from various velocity gradients and at multiple flocculation times.

\section{Materials and methods}

\subsection{Suspension}

The suspended solids in the water sample for this study were produced from a kaolinite solution (prepared with commercial kaolin-Fluka) based on the studies by Pádua [18] and Yukselen and Gregory [19]. The raw water (stock solution) turbidity was 5,000 \pm 200 NTU. Thus, $10 \mathrm{~mL}$ of raw water were diluted to produce $2 \mathrm{~L}$ of water with a turbidity of $25 \pm 2$ NTU.

\subsection{Coagulant}

The coagulant, aluminum sulfate $\left(\mathrm{Al}_{2}\left(\mathrm{SO}_{4}\right)_{3} \cdot 14 \mathrm{H}_{2} \mathrm{O}\right)$, was added at an optimized dosage of $2 \mathrm{mg} \mathrm{Al}^{3+} / \mathrm{L}$ and $\mathrm{pH}$ of 7.5, which was obtained from the coagulation/ flocculation diagram at the mixture conditions defined by preliminary tests with different flash mix $\left(G_{\mathrm{mr}}\right)$ along with times $\left(T_{\mathrm{mr}}\right)$ and flocculation gradients $\left(G_{f}\right)$ and times $\left(T_{f}\right)$. So the preliminary mixture studies indicate: $G_{\mathrm{mr}}$ of $800 \mathrm{~s}^{-1} ; T_{\mathrm{mr}}$ of $10 \mathrm{~s} ; G_{f}$ of $45 \mathrm{~s}^{-1} ; T_{f}$ of $20 \mathrm{~min}$. The $\mathrm{pH}$ was modified with an solution of $\mathrm{Ca}(\mathrm{OH})_{2}, 10 \%$ $(\mathrm{m} / \mathrm{m})$. The coagulation diagram was built from the interpolation of all experimental points.

\subsection{Experimental device and procedure}

The experiments were performed using Jar test bench equipment, as in Yukselen and Gregory [19], coupled to a non-intrusive image capturing system, as illustrated in Fig. 1.

A Vision Research Miro EX4 camera was used for image acquisition. The camera was coupled to a set of lenses that allowed for an $840 \times 640$ pixel resolution with a $0.27-\mathrm{mm}$ pixel size. The treatment of images was performed using the Image-Pro Plus software. The illumination consisted of a laser plane of $2000 \mathrm{~mW}$ of power, with a 532-nm wavelength (due to the peak of camera sensibility) and a 2-mm thickness. The light plane was adjusted in the focus of the image capture system to allow acquisition control at the position of interest. The main advantage of the non-intrusive method is that the samples can be analyzed without risk of sample deformation in association with breakage of flocs. The image analysis results were used to determine the relative proportions of 19 size classes (listed in Table 1, determined by preliminary tests). The same acquisition system was also used to determine the fractal dimension based on perimeter
$\left(D_{f}\right)$, as per Eq. (2). For more details of image acquisition and treatment procedures, references $[20,21]$ can be consulted.

The centers of mass of the particle size distribution (MMD) and of the particle volume distribution (VMD) were determined by solving Eqs. (3) and (4), respectively. Three dimensions were identified to evaluate the particles: the minimum, the mean, and the maximum. The minimum dimension, defined as $D_{\min }$ is the length of the shortest line that connects two points of the floc boundary and passes through the centroid. The mean dimension $\left(D_{\text {mean }}\right)$ is the mean length of the diameters (i.e. passing through the centroid) measured at $2^{\circ}$ steps for the $0-360^{\circ}$ interval. The maximum dimension $\left(D_{\max }\right)$ is the length of the longest line that connects two points of the floc boundary and passes through the centroid. Flocs areas were determined using the software algorithm from the $2 \mathrm{D}$ projection.

$$
\begin{aligned}
& \mathrm{MMD}=\sum_{c=1}^{m} f_{c} c \\
& \mathrm{VMD}=\sum_{c=1}^{m} f_{v} c
\end{aligned}
$$

where $f_{c}$ is the fraction of particles per class $c$; $f_{v}$ is the volume fraction of particles per class $c$ (the volume is calculated using the geometric mean $\left(d_{p}\right)$ for each size class interval); $c$ is a size class (of $m=19$ total size classes, with size ranges that correspond to those listed in Table 1).

To verify the floc morphological characteristics, images were obtained during the final $10 \mathrm{~s}$ of flocculation (for each $T_{f}$ ), at a $10-\mathrm{Hz}$ acquisition rate. Finally, 712,511 flocs were evaluated in the entire process in terms of their PSD, PVD, and morphological characteristics (fractal diameter $\left(D_{f}\right)$, mean ( $D_{\text {med }}$ ), minimum $\left.\left(D_{\min }\right)\right)$, and maximum $\left(D_{\max }\right)$ diameters, with a mean sample error of less than $1 \%$ for a $99 \%$ reliability.

Water treatability experiments were performed for mean flocculation gradients $\left(G_{f}\right)$ of $20,30,40,50$, and $60 \mathrm{~s}^{-1}$ at flocculation times $\left(T_{f}\right)$ of $10,20,30,40$, 50 , and $60 \mathrm{~min}$. The tests were performed independently, that is, all of the $T_{f}$ values were evaluated for each $G_{f}$ value, and the water treatability results, together with the acquisition of the floc images, were obtained for each combination (Fig. 2). The settling efficiency was calculated as the ratio between the initial turbidity $\left(N_{0}\right)$ and the supernatant turbidity $(N)$, and the settling efficiencies for the floc settling velocities of $0.5,1.5,2.5,3.5$, and 


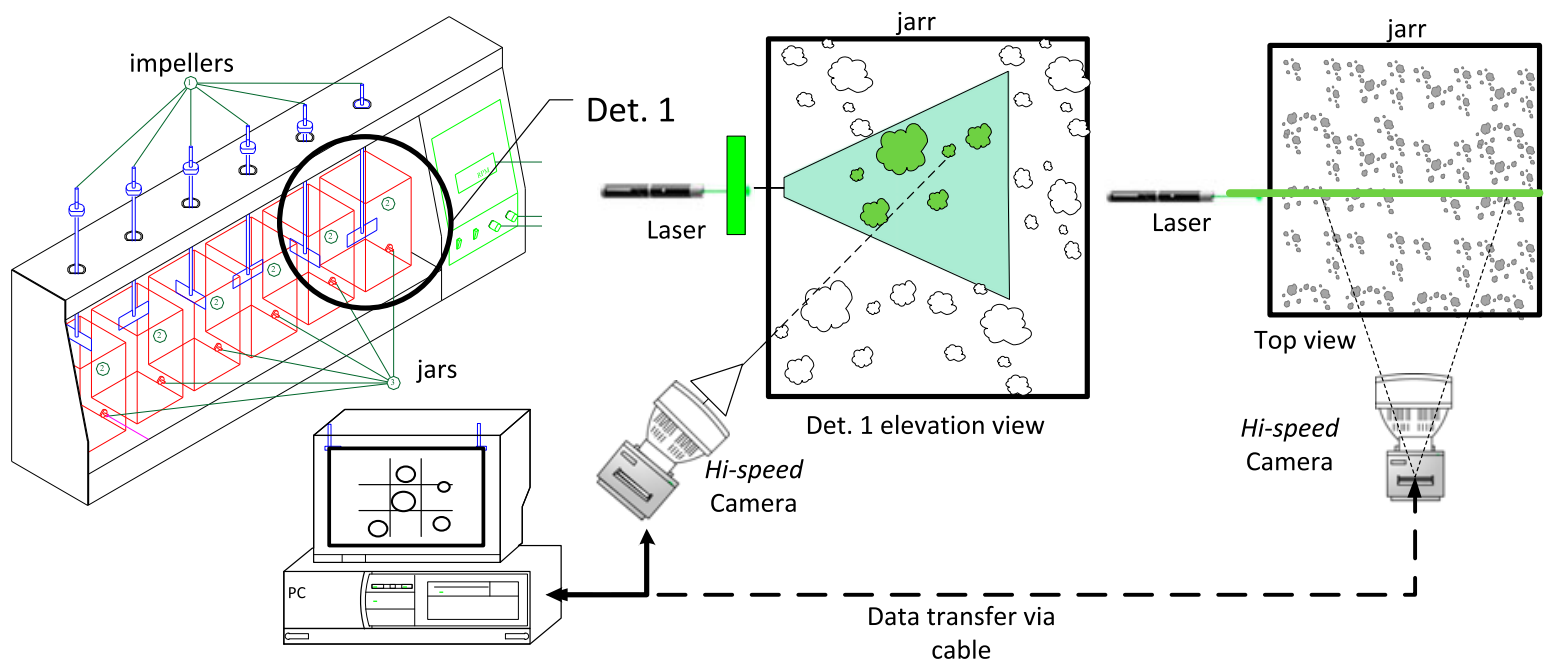

Fig. 1. Schematic illustration of experimental device (Jartest, Personal Computer, Digital Camera, Laser). Visual field of $216 \times 162 \mathrm{~mm}$. Focal distance of $100 \mathrm{~mm}$. Focus' line perpendicular to laser sheet.

Table 1

Particle sizes by class

\begin{tabular}{llll}
\hline Channel $(-)$ & Minimum size $(\mu \mathrm{m})$ & Maximum size $(\mu \mathrm{m})$ & $d_{p}{ }^{\mathrm{a}}(\mu \mathrm{m})$ \\
\hline 1 & 1 & 125 & 11 \\
2 & 125 & 250 & 185 \\
3 & 250 & 375 & 321 \\
4 & 375 & 500 & 433 \\
5 & 500 & 625 & 559 \\
6 & 625 & 750 & 685 \\
7 & 750 & 875 & 810 \\
8 & 875 & 1,000 & 935 \\
9 & 1,000 & 1,125 & 1,061 \\
10 & 1,125 & 1,250 & 1,186 \\
11 & 1,250 & 1,375 & 1,311 \\
12 & 1,375 & 1,500 & 1,436 \\
13 & 1,500 & 1,625 & 1,561 \\
14 & 1,625 & 1,750 & 1,686 \\
15 & 1,750 & 1875 & 1811 \\
16 & 1875 & 2000 & 1936 \\
17 & 2000 & 2,125 & 2062 \\
18 & 2,250 & 2,187 \\
19 & 2,125 & 2,375 & 2,312 \\
\hline
\end{tabular}

${ }^{\mathrm{a}} \mathrm{Geometric}$ mean diameter of the class.

$5.0 \mathrm{~cm} / \mathrm{min}$ were compared. It is important to mention that settling velocities are measured indirectly, based on the sampling of supernatant from a fixed point of the jar in different times after flocculation has ended.

Fig. 3 depicts the relationships among the parameters characterizing the settling performance with the direct measurements of particle distribution. The settling parameters (grouped in " $x$ " in Fig. 3; i.e. the $N_{0} / N$ ratios for the evaluated values of $G_{f}, T_{f}$, and $V_{s}$ ) were each correlated individually with the direct measurements of particle size (i.e. $D_{f}, D_{\min }$ $D_{\text {mean }}$ and $D_{\text {max }}$ ), MMD, and VMD (grouped in "Y" in Fig. 3). 


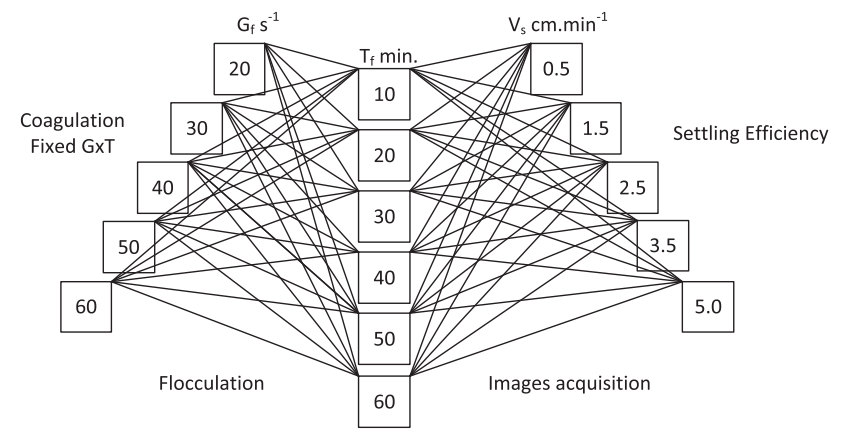

Fig. 2. Schematic of the experimental design for flocculation tests. In which: $G_{f}$ is gradient of velocity; $T_{f}$ is time of flocculation; $V_{s}$ is the average sedimentation velocity; $G$ is gradient velocity to flash mix; $T$ is time of flash mix.

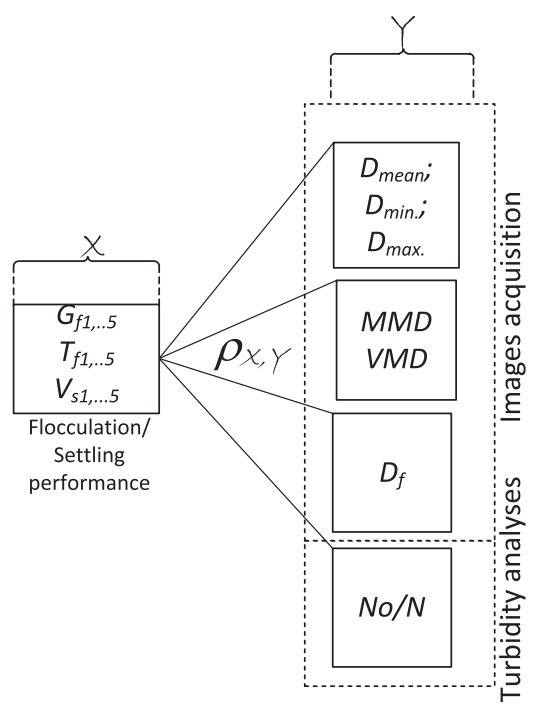

Fig. 3. Schematic of the correlations $(\rho)$ among $X$ and $Y$ variables.

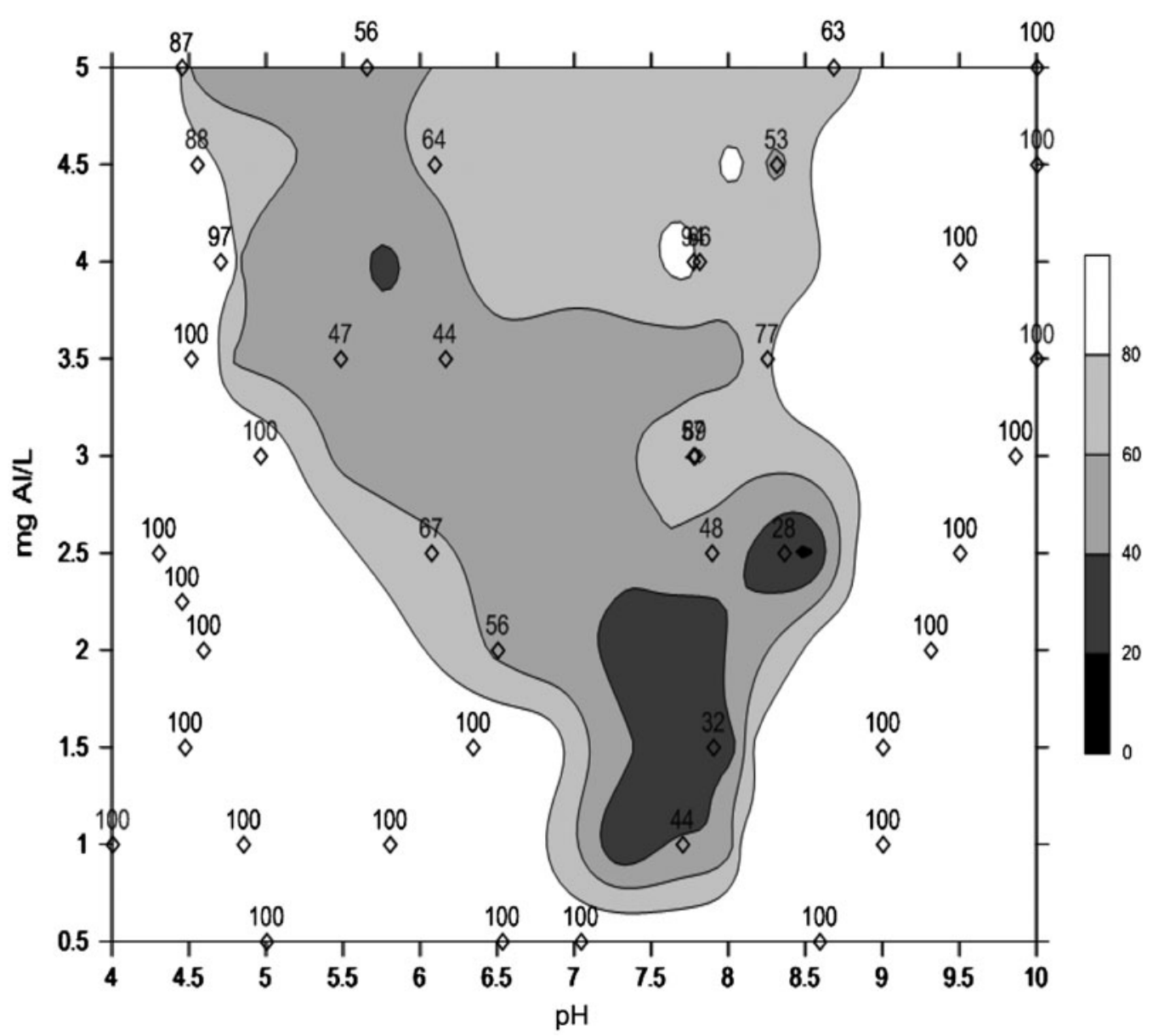

Fig. 4. $\mathrm{Al}^{3+}$ coagulation diagram. Contour represents the percentage of residual turbidity. 
(a)

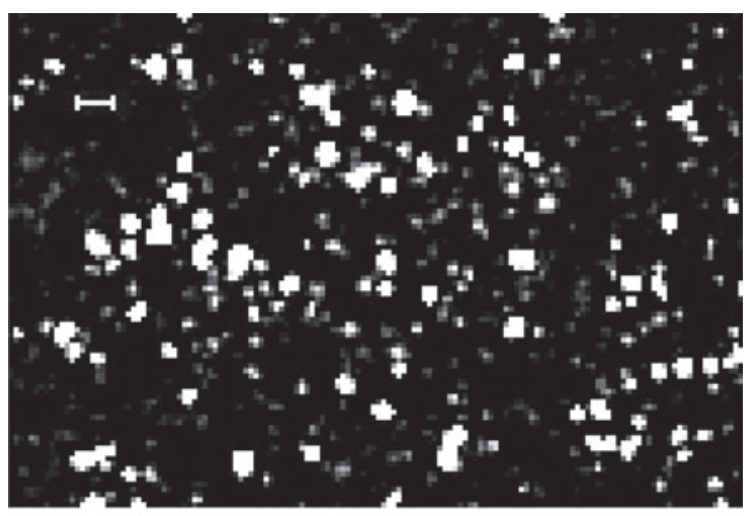

(b)

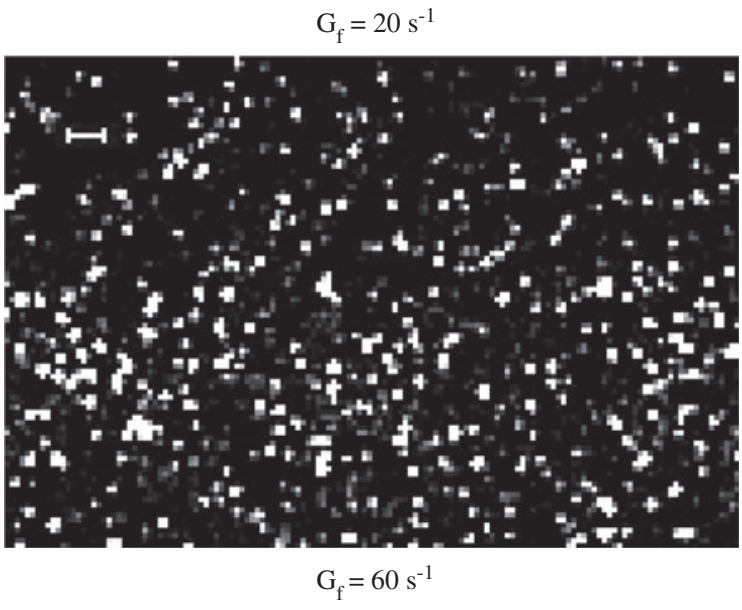

Fig. 5. Images of flocs at $T_{f}=60 \mathrm{~min}$. Image of $2^{8}$ bits, threshold of 165. (a) $G_{f}=20 \mathrm{~s}^{-1}$ and (b) $G_{f}=60 \mathrm{~s}^{-1}$.

\section{Results and discussion}

\subsection{Evolution of the settling performance parameters during flocculation under varying flocculation conditions}

Fig. 4 presents the $\mathrm{Al}^{3+}$ coagulation diagram from which the optimal dosage $\left(2 \mathrm{mg} \mathrm{Al}{ }^{3+} / \mathrm{L}\right.$ at $\left.\mathrm{pH} 7.5\right)$ was adopted for the flocculation/settling tests. Fig. 5 presents two examples of images acquired under differing flocculation conditions, and the PSDs of these images clearly differ accordingly. The particles flocculated with a $G_{f}$ of $20 \mathrm{~s}^{-1}$ were larger than those with a $G_{f}$ of $60 \mathrm{~s}^{-1}$, at a $T_{f}$ of $60 \mathrm{~min}$.

Fig. 6 depicts the evolution of turbidity, normalized by the $N_{0} / N$ ratio, for the velocity gradients of $G_{f}$ from 20 to $60 \mathrm{~s}^{-1}$. The evaluation of these results reveals two important facts: (i) for a fixed $T_{f}$, a change in $G_{f}$ results in a change in performance $\left(N_{0} / N\right)$; and (ii) for a given $G_{f}$, the performance plateaus at a certain $T_{f}$, suggesting the attainment of an equilibrium condition, from which time, there is no change in the settling performance for the given constant settling velocity. However, the settling performance also depends on the associated settling velocity, which, in turn, is related to the apparent rate of surface application in a continuous flow unit.

The rapid attainment of the equilibrium of floc aggregation and disaggregation may explain the small magnitude of the change in efficiency that results from an increase in $T_{f}$ (for a given $G_{f}$ ), which is a welldefined behavior. The highest turbidity removal efficiencies were obtained for a $G_{f}$ of $20 \mathrm{~s}^{-1}$, with a tendency for a reduction in the efficiency of removal with an increase in $G_{f}$. As expected, the efficiency values obtained for higher settling velocities were smaller than those obtained for lower settling velocities. The turbidity removal efficiency decreases with an increase in $G_{f}$ at a settling velocity of $2.5 \mathrm{~cm} / \mathrm{min}$, which is compatible with the conventional decanters in Water Treatment Stations. Notably, the relationship between the turbidity and the concentration of PM is not well defined for wide ranges of turbidity, as verified by Yao et al. [12]. Thus, the investigation of direct size measurements may bring more precision to the evaluation of the settling performance of PM.

\subsection{Evolution of direct particle measurement parameters under varying flocculation conditions}

The flocs that formed at higher $G_{f}$ values had lower $D_{\text {min }}, D_{\text {mean }}$ and $D_{\max }$ values (Fig. 7 ), which explains why settling becomes more difficult when the $G_{f}$ increases, as reflected by the decrease in the removal efficiency. When the $G_{f}$ increases from 20 to $30 \mathrm{~s}^{-1}$, the mean values of $D_{\max }, D_{\text {mean }}$ and $D_{\text {min }}$ decrease from 0.8 to $0.6 \mathrm{~mm}$, from 0.65 to $0.5 \mathrm{~mm}$, and from 0.5 to $0.4 \mathrm{~mm}$, respectively. The values of $D_{\max }$, $D_{\text {mean }}$ and $D_{\min }$ for $G_{f}$ values of 40,50 , and $60 \mathrm{~s}^{-1}$ were similar to those obtained for a $G_{f}$ of $30 \mathrm{~s}^{-1}$, with a slight tendency for a decrease with an increase in the $G_{f}$. As previously mentioned, the size of the flocs, which directly influences the settling velocity, is closely related to the $G_{f}$ and decreases as the latter increases.

Table 2 presents the mean values of $D_{\max }, D_{\text {mean }}$ and $D_{\min }$ for the $G_{f}$ values of $30,40,50$, and $60 \mathrm{~s}^{-1}$ (not shown in Fig. 7). The values are very similar among these $G_{f}$ values, which suggests that the flocs are rapidly stabilized.

Table 3 presents the mean values of the experimentally measured diameters and the diameters estimated using Eq. (1), after log-log transformation. The attainment of a stable floc size is demonstrated by the low values of the mean errors between the experimental data and those calculated by Eq. (1), which is thus valid for the estimation of the diameter of a stabilized floc. 

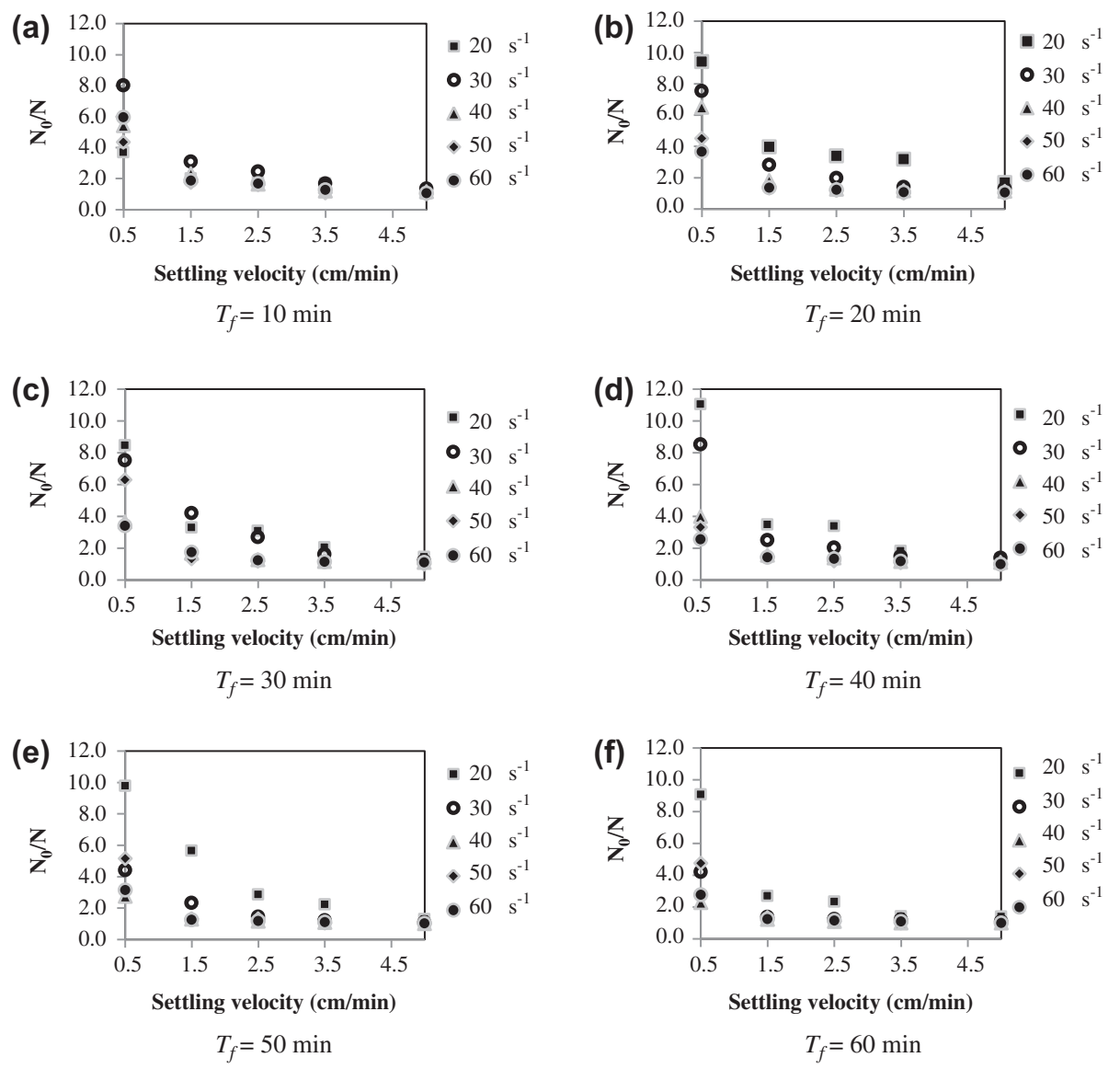

Fig. 6. Relationship between the $N_{0} / N$ ratio (turbidity of the raw water/turbidity of the supernatant of the flocculated water) and the settling velocity for the evaluated $G_{f}$ and $T_{f}$ values. (a) $T_{f}=10 \mathrm{~min}$; (b) $T_{f}=20 \mathrm{~min}$; (c) $T_{f}=30 \mathrm{~min}$; (d) $T_{f}=40 \mathrm{~min} ;(\mathrm{e}) T_{f}=50 \mathrm{~min}$; and (f) $T_{f}=60 \mathrm{~min}$.

(a)

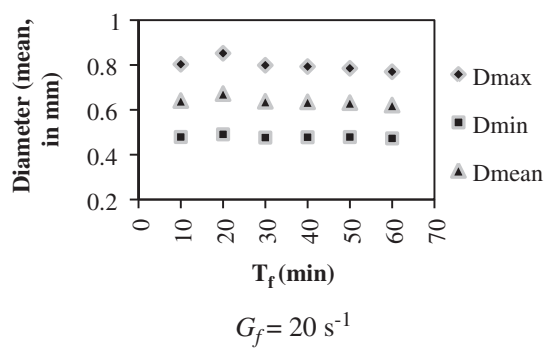

(b)

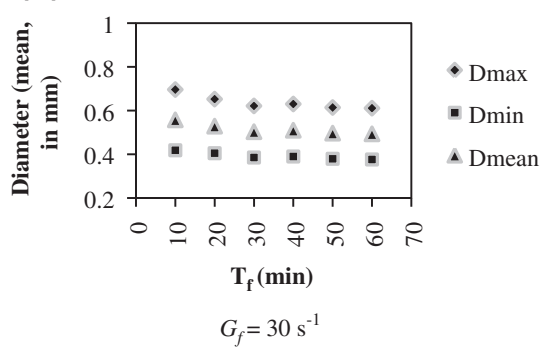

Fig. 7. Temporal evolution of the mean values of the minimum, mean, and maximum particle diameters formed for $G_{f}$ values of (a) 20 and (b) $30 \mathrm{~s}^{-1}$.

The mean values of the floc diameters may not be representative of their size distribution in the suspension and, consequently, of their removal efficiency because extreme values can exert a considerable influence on mean values. In other words, similar mean values can be calculated from very different PSDs. However, the values obtained for the evaluated velocity gradients, considering small time intervals, demonstrate the tendency for an increase in the removal efficiency with an increase in the mean floc particle size. The particle size is closely linked to the solid/liquid separation processes in water treatment systems, and this relationship can vary by technology. The particle structure must be neither too compact nor 
Table 2

Mean values of $D_{\max }, D_{\text {mean, }}$ and $D_{\min }$ for $G_{f}$ values of 40,50 , and $60 \mathrm{~s}^{-1}$

\begin{tabular}{|c|c|c|c|c|c|c|c|c|c|}
\hline \multirow[b]{2}{*}{$\begin{array}{l}T_{f} \\
(\mathrm{~min})\end{array}$} & \multicolumn{3}{|c|}{$G_{f}=40 \mathrm{~s}^{-1}$} & \multicolumn{3}{|c|}{$G_{f}=50 \mathrm{~s}^{-1}$} & \multicolumn{3}{|c|}{$G_{f}=60 \mathrm{~s}^{-1}$} \\
\hline & $\begin{array}{l}D_{\max } \\
(\mathrm{mm})\end{array}$ & $\begin{array}{l}D_{\min } \\
(\mathrm{mm})\end{array}$ & $\begin{array}{l}D_{\text {mean }} \\
(\mathrm{mm})\end{array}$ & $\begin{array}{l}D_{\max } \\
(\mathrm{mm})\end{array}$ & $\begin{array}{l}D_{\min } \\
(\mathrm{mm})\end{array}$ & $\begin{array}{l}D_{\text {mean }} \\
(\mathrm{mm})\end{array}$ & $\begin{array}{l}D_{\max } \\
(\mathrm{mm})\end{array}$ & $\begin{array}{l}D_{\min } \\
(\mathrm{mm})\end{array}$ & $\begin{array}{l}D_{\text {mean }} \\
(\mathrm{mm})\end{array}$ \\
\hline 10 & 0.63 & 0.39 & 0.51 & 0.67 & 0.43 & 0.57 & 0.63 & 0.38 & 0.51 \\
\hline 20 & 0.60 & 0.38 & 0.49 & 0.68 & 0.44 & 0.58 & 0.65 & 0.38 & 0.52 \\
\hline 30 & 0.63 & 0.38 & 0.51 & 0.66 & 0.39 & 0.53 & 0.61 & 0.36 & 0.48 \\
\hline 40 & 0.64 & 0.39 & 0.52 & 0.67 & 0.40 & 0.53 & 0.61 & 0.36 & 0.49 \\
\hline 50 & 0.64 & 0.39 & 0.52 & 0.70 & 0.40 & 0.55 & 0.61 & 0.35 & 0.48 \\
\hline 60 & 0.57 & 0.35 & 0.46 & 0.66 & 0.38 & 0.52 & 0.59 & 0.34 & 0.47 \\
\hline
\end{tabular}

Table 3

Mean values of experimentally measured diameters $\left(D_{\text {measured }}\right)$ and the diameters obtained by solving Eq. (1) $\left(D_{\text {stable }}\right)$

\begin{tabular}{|c|c|c|c|c|c|c|c|c|c|}
\hline \multirow[b]{2}{*}{$\begin{array}{l}G_{f} \\
\left(s^{-1}\right)\end{array}$} & \multicolumn{3}{|c|}{ Mean $D_{\max }(C=1.32 ; \beta=0.19)$} & \multicolumn{3}{|c|}{ Mean $D_{\text {mean }}(C=1.07 ; \beta=0.19)$} & \multicolumn{3}{|c|}{ Mean $D_{\min }(C=1.18 ; \beta=0.21)$} \\
\hline & $\begin{array}{l}D_{\text {stable }} \\
(\mathrm{mm})\end{array}$ & $\begin{array}{l}D_{\text {measured }} \\
(\mathrm{mm})\end{array}$ & $\begin{array}{l}\text { Error } \\
(\%)\end{array}$ & $\begin{array}{l}D_{\text {stable }} \\
(\mathrm{mm})\end{array}$ & $\begin{array}{l}D_{\text {measured }} \\
(\mathrm{mm})\end{array}$ & $\begin{array}{l}\text { Error } \\
(\%)\end{array}$ & $\begin{array}{l}D_{\text {stable }} \\
(\mathrm{mm})\end{array}$ & $\begin{array}{l}D_{\text {measured }} \\
(\mathrm{mm})\end{array}$ & $\begin{array}{l}\text { Error } \\
(\%)\end{array}$ \\
\hline 20 & 0.75 & 0.80 & -6 & 0.61 & 0.64 & -6 & 0.46 & 0.48 & -5 \\
\hline 30 & 0.69 & 0.64 & 7 & 0.55 & 0.52 & 7 & 0.42 & 0.39 & 6 \\
\hline 40 & 0.65 & 0.62 & 5 & 0.52 & 0.50 & 3 & 0.39 & 0.38 & 3 \\
\hline 50 & 0.62 & 0.67 & -9 & 0.49 & 0.55 & -12 & 0.37 & 0.41 & -10 \\
\hline 60 & 0.59 & 0.62 & -4 & 0.47 & 0.49 & -4 & 0.35 & 0.36 & -3 \\
\hline
\end{tabular}

(a)

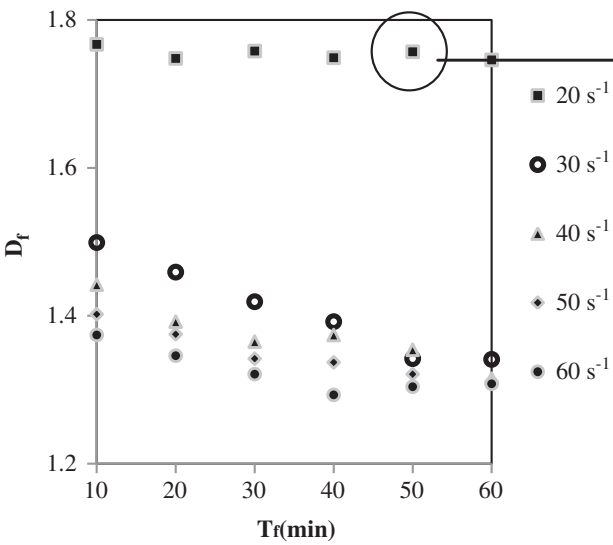

Temporal evolution of fractal diameter

$\left(D_{f}\right)$ (b)

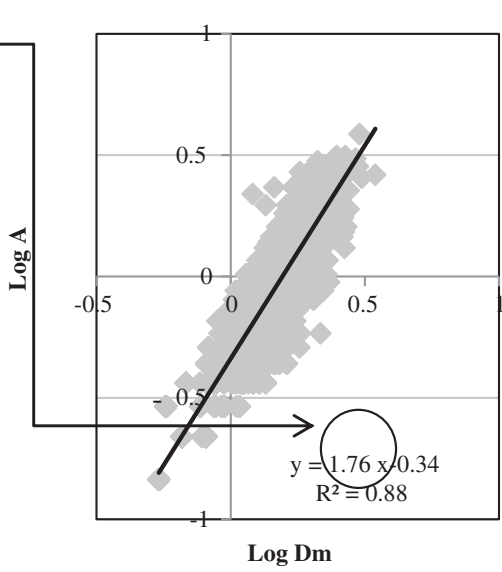

Example of the determination of the fractal diameter $\left(D_{f}\right)$ from image attributes. $G_{f}=20 \mathrm{~s}^{-1}$ and $T_{f}=50 \mathrm{~min}$

Fig. 8. Fractal diameters $\left(D_{f}\right)$ of particles formed at various $G_{f}$ values as a function of the $T_{f}$. (a) Temporal evolution of fractal diameter and (b) Example of the determination of the fractal diameter.

too porous as a result of the phenomena involved in the separation process. Hence, the success of the separation process is the result of a set of attributes and not of an isolated characteristic of the floc. Regarding settling, a compact (dense) particle has a higher settling velocity than a porous particle of the same 


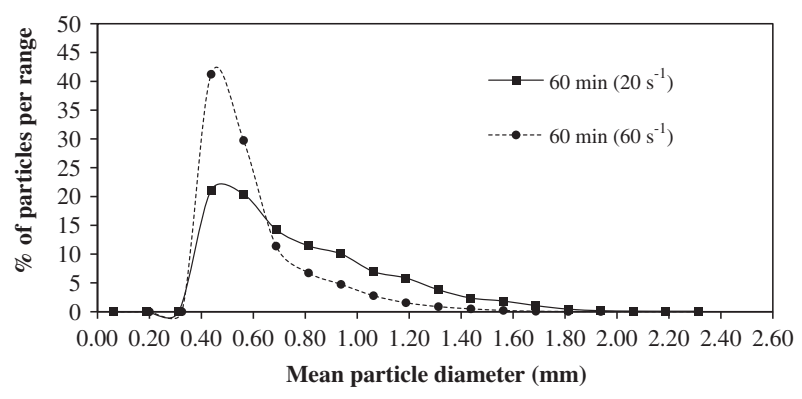

Fig. 9. PSDs for $G_{f}$ values of 20 and $60 \mathrm{~s}^{-1}$.

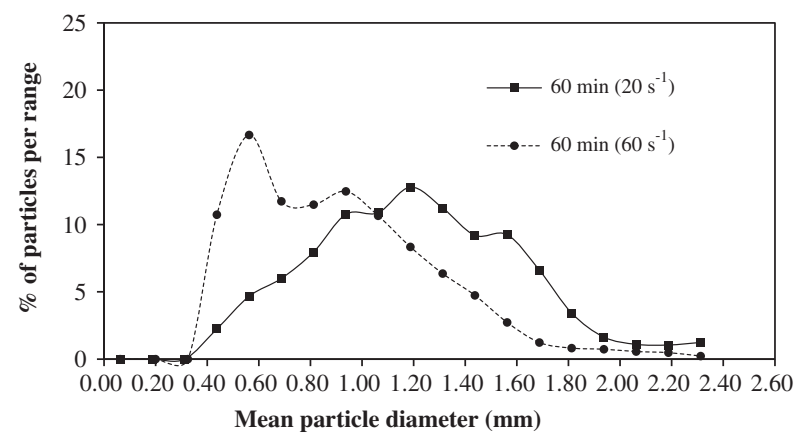

Fig. 10. PVD curves for the $G_{f}$ values of 20 and $60 \mathrm{~s}^{-1}$ at a $T_{f}$ of $60 \mathrm{~min}$.

volume and material constitution. This behavior can be observed by the comparison of the results for the $G_{f}$ of $20 \mathrm{~s}^{-1}$ compared to the other $G_{f}$ values. The best turbidity removal efficiencies are observed in this case, and the mean values of $D_{\text {min, }} D_{\text {mean }}$ and $D_{\text {max }}$ are higher. Therefore, there is a tendency for a decrease in the turbidity removal efficiency with an increase in $G_{f}$ for a given $T_{f}$. The analysis of the fractal diameters

(a)

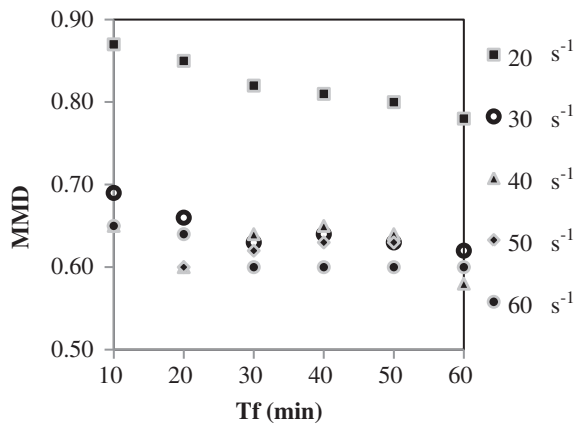

Variation in MMD as a function of flocculation time for various $G_{f}$ values indicates the same pattern; the turbidity removal efficiency increases with an increase in fractal diameter. In addition, the curves for the fractal diameter as a function of time (Fig. 8) for flocs obtained from various $G_{f}$ also illustrate the stabilization of the particles in terms of their morphological characteristics.

The resulting equations follow the form of Eq. (2) after a log-log transformation is applied. Hence, the multiplier coefficient represents the fractal diameter of the set of flocs $\left(D_{f}\right)$. The value of $D_{f}$ decreases as the $G_{f}$ increases, as also reported by Huang [22], and $D_{f}$ also decreases as the $T_{f}$ increases, as reported by Chakraborti et al. [23]. From these results, it is presumed that as the $G_{f}$ and $T_{f}$ values increase, the erosive effect of the $G_{f}$ on the non-Euclidean and, consequently, less compact particle increases. However, a number of studies have reported an increase in $D_{f}$ with an increase in $G_{f}$, e.g. Li et al. [24]. In the present study, as indicated by the small changes observed in the value of $D_{f}$, morphological stability was achieved within the first $10 \mathrm{~min}$ of flocculation $\left(T_{f}=10 \mathrm{~min}\right)$. Thus, it was not possible to establish a good temporal relationship between the evolution of $D_{f}$ and the settling characteristics of the particles in suspension in this study.

The PSD can also be evaluated as a tool to analyze the flocculation process. Fig. 9 presents the PSD curves for the $G_{f}$ values of 20 and $60 \mathrm{~s}^{-1}$ at a $T_{f}$ of $60 \mathrm{~min}$. For the lower $G_{f}$, the proportion of smaller particle size is relatively lower, and there is an increased predominance of larger size particles.

The particle frequency of the diameter size class with a mean diameter of $0.44 \mathrm{~mm}$ was approximately $50 \%$ lower for the $20 \mathrm{~s}^{-1}$ PSD compared to the $60 \mathrm{~s}^{-1}$ PSD, with an approximately $30 \%$ reduction in the frequency of the $0.56-\mathrm{mm}$ size class. However, there were

(b)

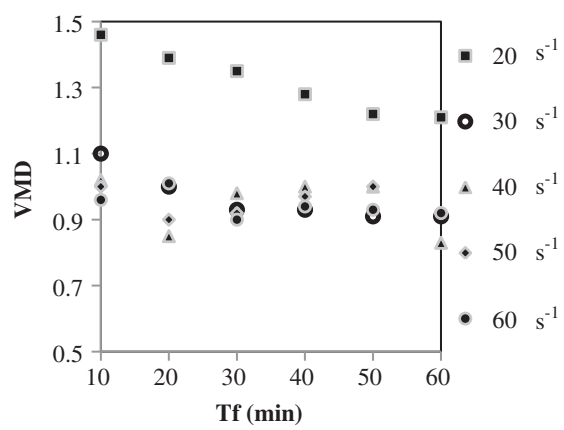

Variation in VMD as a function of flocculation time for various $G_{f}$ values

Fig. 11. Behavior of the center of mass as a function of time. (a) MMD and (b) VMD. 
Table 4

Correlations among parameters of system operation $\left(G_{f}, T_{f}\right)$, treatability $\left(N_{0} / N\right)$ for various $V_{s}$ (settling velocities), and representative floc size distribution characteristics $\left(D_{f}, \mathrm{MMD}, \mathrm{VMD}\right)$

\begin{tabular}{|c|c|c|c|c|c|c|c|c|c|}
\hline & $G_{f}$ & $D_{f}$ & MMD & VMD & $N_{0} / N V_{s 5.0}$ & $N_{0} / N V_{s} 3.5$ & $N_{0} / N V_{s} 2.5$ & $N_{0} / N V_{s} 1.5$ & $N_{0} / N V_{s 0.5}$ \\
\hline$G_{f}$ & 1.00 & & & & & & & & \\
\hline$D_{f}$ & -0.86 & 1.00 & & & & & & & \\
\hline MMD & -0.73 & 0.97 & 1.00 & & & & & & \\
\hline VMD & -0.64 & 0.93 & 0.99 & 1.00 & & & & & \\
\hline$N_{0} / N V_{s 5.0}$ & -0.90 & 0.98 & 0.95 & 0.91 & 1.00 & & & & \\
\hline$N_{0} / N V_{s} 3.5$ & -0.79 & 0.99 & 0.98 & 0.95 & 0.97 & 1.00 & & & \\
\hline$N_{0} / N V_{s} 2.5$ & -0.86 & 0.99 & 0.98 & 0.94 & 0.99 & 0.98 & 1.00 & & \\
\hline$N_{0} / N V_{S 1.5}$ & -0.94 & 0.95 & 0.90 & 0.85 & 0.99 & 0.92 & 0.97 & 1.00 & \\
\hline$N_{0} / N V_{s} 0.5$ & -0.99 & 0.88 & 0.77 & 0.68 & 0.92 & 0.83 & 0.88 & 0.95 & 1.00 \\
\hline
\end{tabular}

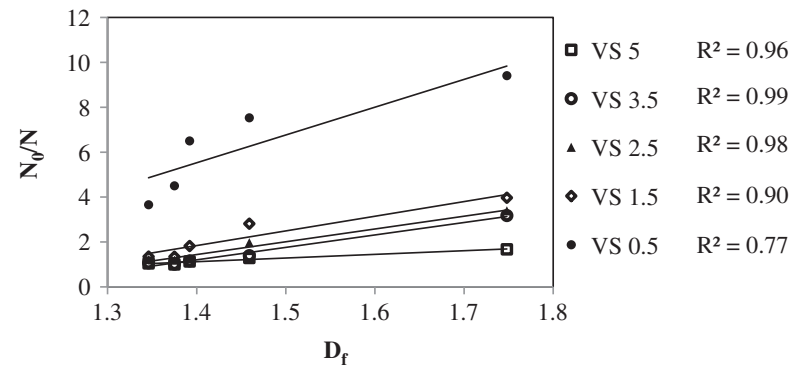

Fig. 12. Relationship between $N_{0} / N$ and $D_{f}$.

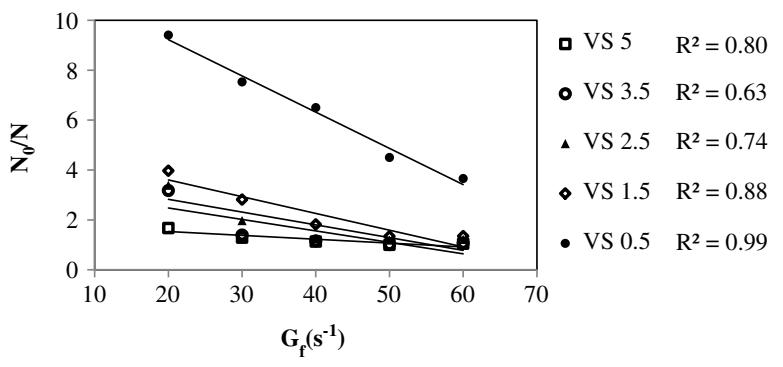

Fig. 13. Relationship between $N_{0} / N$ and $G_{f}$.

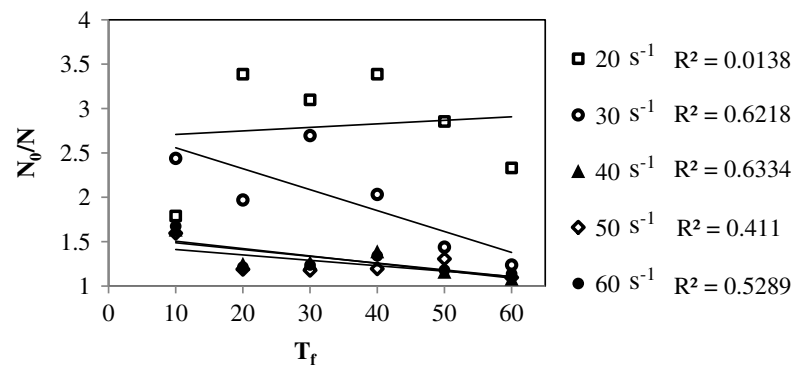

Fig. 14. Relationship between $N_{0} / N$ and $T_{f}$ for various $G_{f}$ values and a $V_{s}$ of $2.5 \mathrm{~cm} / \mathrm{min}$. simultaneous increases of approximately 20, 40, 50, 60, and $75 \%$ in the particle frequencies of the $0.69,0.81$, $0.94,1.06$, and 1.2-mm size classes, respectively. This variation explains the variation in the treatability results. Larger particles are known to typically have higher settling velocities and are thus more effectively removed by the differential settling process, which favors the removal of particles that cause turbidity.

The distribution of particle concentration can also be evaluated by PVD, as shown in Fig. 10. For a $G_{f}$ of $20 \mathrm{~s}^{-1}$, there is a displacement to the right, the region larger particle sizes, compared to the $G_{f}$ of $60 \mathrm{~s}^{-1}$.

The differences in the PVDs graphed in Fig. 10 highlight the importance of particle size in settling. The higher concentration of larger particles for the $G_{f}$ of $20 \mathrm{~s}^{-1}$ clearly demonstrates the driving influence of the larger particles on the global volume calculation. In other words, the volume of the larger size particles exerts a strong influence on turbidity removal because large particles have better settling characteristics and their presence favors flocculation by differential settling, as previously mentioned.

\subsection{Analysis of the correlation of the flocculation/settling performance with the directly measured parameters}

The evolutions of the centers of mass of the particle size distribution (MMD-Mass Median Diameter) and of the particle volume distribution (VMD-Volume Median Diameter) were also evaluated. The behavior of the center of mass as a function of time is shown in Fig. 11, and the correlations among these parameters and the other measured parameters at the $T_{f}$ of $20 \mathrm{~min}$ are listed in Table 4.

Notably, parameters evaluated in this study are not well correlated among the various flocculation times trend. The results demonstrate that steady-state 
was attained rapidly; thus, temporal correlations were not so significant. A $T_{f}$ of $20 \mathrm{~min}$ for a $G_{f}$ of $20 \mathrm{~s}^{-1}$ was chosen to present the correlations among floc size and settling parameters because these are typical conditions of conventional water treatment systems.

The strong inverse correlations between the $G_{f}$ and the $N_{0} / N$ ratio across settling velocities $\left(N_{0} / N V_{s}\right)$ indicate that higher $G_{f}$ values are associated with lower removal efficiency values. Thus, the smaller flocs are more difficult to remove by settling. The decrease in floc removal efficiency with an increase in $G_{f}$ is also associated with decreases in the MMD, VMD, and $D_{f}$ as well; therefore, all of these parameters follow the same pattern, each in its own proportion. The parameters that describe the floc morphological characteristics are also noted to be strongly and positively correlated with each other. Fig. 12 presents the relationship between $N_{0} / N$ and $D_{f}$ (for various $G_{f}$ values), considering a $T_{f}$ of $20 \mathrm{~min}$, and Fig. 13 presents the correlation curves between $N_{0} / N$ and $G_{f}$ at a $T_{f}$ of $20 \mathrm{~min}$. The analysis of water treatability as a function of the directly measured parameters of flocculation monitoring provides information that is more precise and more coherent with respect to the process dynamics. The joint observation of this group of variables has practical coherence and provides assistance for the better control of treatment units that employ solid/liquid separation. These observations are in accordance with references [10-12], in which direct monitoring by means of MMD, VMD, and $D_{\text {mean }}$ is pointed out as a possibility to improve flocculation process. In practical terms, the way the process can be improved depends on the application and/or the development of equipment which is able to rapid measure PSD.

In contrast, the analysis of the evolution of floc morphology and settling with flocculation time did not reveal a coherent behavior among the parameters. Fig. 14 presents the evaluation of the turbidity removal efficiency as a function of $T_{f}$ for a settling velocity of $2.5 \mathrm{~cm} / \mathrm{min}$.

As a function of the variation in of $G_{f}$, poor correlations were observed between the floc morphology and settling parameters, in addition to the absence of a well-defined behavior as a function of the change in $G_{f}$. Temporal analyses of the other parameters were also performed with similar results.

\section{Conclusions}

The results of this study highlight the importance of the analysis and the understanding of the direct measurement of representative flocculation parameters.
The changes in floc morphological characteristics and floc particle sizes and volume distributions directly and sensitively reflect the changes in removal efficiencies. Hence, the parameters of the directly measured flocculation parameters were sensitive to changes in the flocculation removal efficiency parameters. The morphological analysis of flocs by their minimum, mean, maximum, and fractal diameters is important when performed together with PSD and PVD analyses. These parameters have strong correlations among various $G_{f}$ values; however, the temporal correlations are weak because steady-state is attained rapidly. These results prompt further research, in order to improve methods for implementation of a continuous flow device, which can monitor flocculation directly by means of PSD, permitting to control mixture conditions for subsequent treatment units of solid particle removal.

\section{Acknowledgments}

The authors thank the São Paulo Research Foundation (Fundação de Amparo à Pesquisa do Estado de São Paulo-FAPESP. Proc. 2010/50694-0; 2013/256419; 2013/21355-1; 2013/01634-3). The authors are also gratefully to SABESP, Cia de Saneamento Basico do Estado de São Paulo.

\section{References}

[1] M.R. Wiesner, A.M. ASCE, C.R. O'Melia, J. Cohon, Optimal water treatment plant design, J. Environ. Eng. 113 (1987) 567-584.

[2] P.T. Spicer, S.E. Pratsinis, J. Raper, R. Amal, G. Bushell, G. Meesters, Effect of shear schedule on particle size, density, and structure during flocculation in stirred tanks, Powder Technol. 97 (1998) 26-34.

[3] J.J. García-Mesa, J.M. Poyatos, F. Delgado-Ramos, M.M. Muñio, F. Osorio, E. Hontoria, Water quality characterization in real biofilm wastewater treatment systems by particle size distribution, Bioresour. Technol. 101 (2010) 8038-8045.

[4] I.C. Tse, K. Swetland, M.L. Weber-Shirk, L.W. Lion, Method for quantitative analysis of flocculation performance, Water Res. 45 (2011) 3075-3084.

[5] J.R. Bratby, M.W. Miller, G.V.R. Marais, Design of flocculation systems from batch test data, Water S.A. 3 (4) (1977) 173-182.

[6] D.N. Thomas, S.J. Judd, N. Fawcett, Flocculation modelling: A review, Water Res. 33(7) (1999) 1579-1592.

[7] R.C. Klimpel, R. Hogg, Evaluation of floc structures, Colloid. Surface. 55 (1991) 279-288.

[8] J. Gregory, Fundamentals of flocculation, Crit. Rev. Environ. Control 19 (1989) 185-230.

[9] P. Jarvis, B. Jefferson, J. Gregory, S.A. Parsons, A review of floc strength and breakage, Water Res. 39 (2005) 3121-3137. 
[10] S. Hatukai, Y. Bentzur, M. Rebhun, Particle counts and size distribution in system design for removal of turbidity by granular deep bed filtration, Water Sci. Technol. 36(4) (1997) 225-230.

[11] J. Wu, C. He, Experimental and modeling investigation of sewage solids sedimentation based on particle size distribution and fractal dimension, Int. J. Environ. Sci. Technol. 7(1) (2010) 37-46.

[12] M. Yao, J. Nan, T. Chen, Effect of particle size distribution on turbidity under various water quality levels during flocculation processes, Desalination 354 (2014) 116-124.

[13] L.B. Brakalov, A connection between the orthokinetic coagulation capture efficiency of aggregates and their maximum size, Chem. Eng. Sci. 42 (1987) 2373-2383.

[14] R.K. Chakraborti, J.F. Atkinson, J.E. Van Benschoten, Characterization of alum floc by image analysis, Environ. Sci. Technol. 34 (2000) 3969-3976.

[15] S.M. Glover, Y.D. Yan, G.J. Jameson, S. Biggs, Dewatering properties of dual-polymer-flocculated systems, Int. J. Mineral Process. 73 (2004) 145-160.

[16] T. Li, Z. Zhu, D. Wang, C. Yao, H. Tang, The strength and fractal dimension characteristics of alum-kaolin flocs, Int. J. Mineral Process. 82 (2007) 23-29.

[17] T.D. Waite, Measurement and implications of floc structure in water and wastewater treatment, Colloid. Surface. A 151 (1999) 27-41.

[18] V.L. Pádua, Metodologia para determinação dos gradientes de velocidade médios em unidades de floculação de mistura completa com câmaras em série e escoamento contínuo a partir de reatores estáticos [Methodology to determine mean velocity gradients in complete mixture flocculation units with series chambers and continuous flow from static reactors]. Thesis (Masters in Hydraulics and Sanitation), São Carlos, São Carlos School of Engineering, University of São Paulo (Escola de Engenharia de São Carlos, Universidade de São Paulo), 1994, p. 165.

[19] M.A. Yukselen, J. Gregory, The reversibility of floc breakage, Int. J. Mineral Process. 73 (2004) 251-259.

[20] R.B. Moruzzi, M.A.P. Reali, Método para determinação de distribuição de tamanho de microbolhas (DTMB) em sistemas flotação (FAD) para tratamento de águas utilizando a análise de imagem digital [Method for measuring bubbles sizes distribution (BSD) in drinking water treatment flotation (DAF) systems by using digital image analysis], Eng. Sanit. Ambient. 12(3) (2007) 273-283.

[21] R.B. Moruzzi, M.A.P. Reali, Characterization of microbubble size distribution and flow configuration in DAF contact zone by a non-intrusive image analysis system and tracer tests, Water Sci. Technol. 61(1) (2010) 253-262.

[22] H. Huang, Porosity-size relationship of drilling mud flocs: Fractal structure, Clay. Clay Miner. 41(3) (1993) 373-379.

[23] R.K. Chakraborti, K.H. Gardner, J.F. Atkinson, J.E. Van Benschoten, Changes in fractal dimension during aggregation, Water Res. 37 (2003) 873-883.

[24] T. Li, Z. Zhu, D. Wang, C. Yao, H. Tang, Characterization of floc size, strength and structure under various coagulation mechanisms, Powder Technol. 168 (2006) 104-110. 